\title{
Radiographic Evaluation of Long Bone Fractures by using Antibiotic Loaded Bone Cement (ALBC) and Biosynthetic Bone Graft in dogs
}

\author{
P.S. Dakhane ${ }^{1}$, D. U. Lokhande ${ }^{1}$, G. S. Khandekar ${ }^{1}$, G. U. Yadav ${ }^{1 *}$,
} S. D. Tripathi ${ }^{1}$, S. D. Ingole ${ }^{2}$ and D. P. Kadam ${ }^{3}$

${ }^{1}$ Department of Vet. Surgery and Radiology, ${ }^{2}$ Department of Vet. Physiology, ${ }^{3}$ Department of Vet. Pathology, Mumbai Veterinary College, Parel, Mumbai - 12, India Maharashtra Animal and Fisheries Sciences University, Nagpur-06, India

*Corresponding author

\section{Keywords}

Fracture, Long bone, Canine, Antibiotic loaded bone cement (ALBC), Biosynthetic Bone Graft, Radiographic evaluation

Article Info

Accepted: 14 April 2021 Available Online: 10 May 2021

\section{A B S T R A C T}

A total of 24 clinical cases of dogs with long bone fractures were selected for study. All the dogs were divided into 3 groups, viz. Group I, Group II and Group III consisting of $8 \mathrm{dogs}$ in each group. Group I will be treated as control group whereas Group II will be treated with antibiotic loaded bone cement and immobilization of fragments will be done by locking compression plate alone and group III will be treated with locking Compression Plate along with biosynthetic bone graft. The secondary bone fragments will be kept in position by use of wire. Fracture healing was evaluated by radiographic examination in all cases before surgery and just after surgery and also on $2^{\text {nd }}, 4^{\text {th }}$ and $8^{\text {th }}$ week of post operative period. An increase in weight bearing while standing, walking and running was observed, however maximum weight bearing was observed from $30^{\text {th }} \&$ $60^{\text {th }}$ post-operative day in group III. Comparison between groups revealed better weight bearing in group III.

\section{Introduction}

Dog has been considered as "Man's best friend" and an increasing interest has been observed among people of urban as well as rural areas of India to keep them for companionship. A fracture is a break in the continuity of hard tissues like bone or cartilage. The incidence of musculoskeletal injuries has been increasing in recent times. Among the small animal surgical cases, the incidence of fracture is documented to be 
about $17.80 \%$, out of which fracture in dogs constituted to $67 \%$. Among all the fractures, the incidence of long bone fractures constituted to $84.48 \%$ (Ali 2013).

The type of fracture and degree of soft tissue trauma depends upon direction and magnitude of the force that is applied to the bone (Burns, 2010). Fracture repair depends on the fracture configuration and the biological environment of the bone. Advances in fracture fixation have reduced the mortality and morbidity associated with these fractures (Ragunath and Singh, 2008). Locking compression plating system is a recent concept of fracture reduction for the management of unstable diaphyseal and metaphyseal fractures.

Locking intemal fixators allow forcallus formation through increased flexibility in stabilization (Egol et al., 2004). The Locking Compression Plate (LCP) offers the possibility of inserting conventional and locking head screws into specially designed combination holes. This new plate hole design permitted the use of both of standard screws and locking head screws (LHS) resulting in fixed-angle stability.

The healing of fracture is evaluated by conventional radiography; however to use of computed radiography provide better resolution of callus \& fracture. However many times radiograph shows bone healing but animal does not bear weight properly. In the recent past, interest has shifted to finding out the efficacy of some of the degradable and absorbable implants which aid in reduction and get degraded or absorbed after some time resulting in gradual reduction of rigid fixation and allowing fast bone healing. However, still such procedures have not given desirable results. As animal patient is different from human, various work on orthopedic is still in progress. Bioceramics (hydroxyapatite, tricalcium phosphate, dicalcium phosphate, bioactive glass, calcium sulphate), polymers (Polylactic acid, polyglycolic acid and polymethylmethacrylate), metals (stainless steel, titanium and titanium alloys, cobaltchromium) and composites (ceramic metal, ceramic-polymer, ceramic-ceramic) have been tried by several researchers to overcome this (Vardhan et al., 2017).

Polymethylmethacrylate (PMMA)-based bone cement is the most common, commercially available material used in the orthopaedic field to fix cemented prostheses to the hosting bone (Juszczyk et al., 2008). Bone cement or Polymethylmethacrylate (PMMA), has been used in surgical fixation of artificial joints for over 50 years. The primary function of bone cement is to transfer forces from bone to prosthesis (Arora et al., 2013).

Treatment of bone defects is a continuous challenge in orthopaedic surgery. Large defects that result from trauma, infection, resection of tumours, or other causes usually do not heal spontaneously, and surgical intervention is often required. The most widely used technique for the reconstruction of a bone defect is the use of autogenous bone graft. However, the disadvantage of this technique is its limited availability and morbidity at donor site. These disadvantages led to the use allograft and xenograft. But the usage of these materials for bone repair has been associated with the risk of rejection and transfer diseases. To overcome these drawbacks of endogenous and exogenous bone graft, several synthetic bone grafts have been proposed. Particularly, hydroxyapatite (HA) is currently used worldwide in practical applications as a bone substitute due to its close similarities with bone and tooth tissue. HA has been used as a filler for periodontal, periapical defects, alveolar ridge augmentation, and maxillofacial reconstruction. Beta tricalcium phosphate $(\beta$ TCP) was one of the earliest calcium 
phosphate compounds to be used as a bone graft substitute.

\section{Materials and Methods}

A total of 24 clinical cases of dogs with long bone fractures were selected for study. The dogs were divided into 3 groups, viz. Group I, Group II and Group III consisting of 8 dogs each. Group I will be treated as control group whereas Group II will be treated with antibiotic loaded bone cement and immobilization of fragments will be done by locking compression plate alone and group III will be treated with locking Compression Plate along with biosynthetic bone graft. The secondary bone fragments will be kept in position by use of wire.

\section{Post-operative radiographic examination}

Post operative Radiographs were taken immediately after surgery and subsequently on day $2^{\text {nd }}, 4^{\text {th }} \& 8^{\text {th }}$ wk post-operatively and healing of fracture was evaluated on the basis of following radiographic scoring system as per Lane and Sandhu (1987) as follows:

\section{Results and Discussion}

In group I, four cases shows simple transverse fracture at mid shaft region. One case each showed transverse fracture at distal third region, oblique mid shaft fracture, transverse fracture at upper third region and midshaft overriding fracture, respectively.

In group II, three cases showed simple transverse fracture at mid shaft region. Two cases each showed oblique mid shaft fracture, distal third mid shaft. One case showed coolis fracture respectively.

In group III, five cases shows simple transverse fracture at mid shaft region. Two cases showed distal third mid shaft, one case showed oblique spiral midshaft. Coutinho (2012) and Chavan (2013) also reported that the preoperative radiographs were useful for the evaluation of fracture as well as for selection of the proper technique and its repair.

In the present study, fracture was seen, more in male dogs $(75 \%)$ than that of female dogs $(25 \%)$. Several authors also reported higher incidence of fractures in male than in female dogs (Kolata et al., 1974; Phillips, 1979; Balagopalan et al., 1995; Aithal et al., 1999 and Simon et al., 2011) which coincides with the findings of the present study.

Out of the 24 dogs, $50 \%$ dogs were between one to two years of age, $29.16 \%$ were between two to four years of age and $20.83 \%$ were above four years of age.

In breed wise distribution, the percentage of non-descript breed having fracture was recorded to be $83.33 \%, 4.16 \%$ was golden retriever, $4.16 \%$ was Labrador, $4.16 \%$ was Labrador mix while 4.16\% were Lyssa Apso. Maala and Celo (1975) and Aithal et al., (1999) noted that the 'local' dogs or non descript dogs are usually let loose to roam outside freely and thus are more likely to succumb to road accidents.

The most common etiology for long bone fractures was an automobile accident which was seen in $66.0 \%$ dogs. While $20.83 \%$ case of dogs was resulted due to fallen from height while in $12.5 \%$ dogs fracture resulted due to jump from the table or height.

Femur and tibia-fibula were the most commonly affected bones with fracture and each comprising of $25 \%$ and $37.5 \%$ while $37.5 \%$ dogs had fracture, in radius and ulna. Aithal et al., (1999) recorded that of all the long bones fracture, highest number of fractures were seen in femur (38.56\%), 
followed by tibia/fibula $(17.16 \%)$, radius/ulna $(16.92 \%)$ and humerus $(7.71 \%)$. According to Hansen (2003), femur is the bone, that fractured most often in dogs and cats.

Time elapsed since long bone fracture with bone loss was found to be two to four days in case of $62.5 \%$ dogs while five to nine days in case of $37.5 \%$ dogs. It is attributed that when the case is fresh and immobilized as soon as possible, the outcome will be good. Earlier immobilization of fracture will lead to less complications and better results ( $\mathrm{Xu}$ et al., 1998).

Post operative Radiological Union score by computed radiography was studied after surgery (day 0 ) and subsequently on $2^{\text {nd }}, 4^{\text {th }}$ and $8^{\text {th }}$ week post-operatively and were compared. In group I, II \& III according to RUS all case after surgery shows score 1 i.e no fracture line visible and no callus formation.

\section{Group I}

On $2^{\text {nd }}$ week, radiographic examination revealed perfect fixation of the plate with one case of implant failure. In five cases, i.e. in $62.5 \%$ of cases, no periosteal reaction was observed while two cases i.e. $25 \%$ of cases depicted initiation of periosteal reaction at a distance from the fracture line with trace callus formation and one case found bending of plate on $3^{\text {rd }}$ day of post operative due to dog was uncooperative and very aggressive. In all the cases of this group, full fracture line was visible (score 0). According to Rajhans (2013) and Kumar (2016), there may be mild periosteal reaction around the fracture site and the area of bone loss with trace callus formation. On $2^{\text {nd }}$ week of post-operative, three cases i.e. $37.5 \%$ of cases showed score 0 , four cases i.e. $50 \%$ of cases depicted score 0 and one cases i.e. $12.5 \%$ of cases revealed primary callus formation between the periosteal and intercortical space.

Bridging callus was beginning to form between the fractured fragments and the area of bone loss. The fracture gap had reduced and the fracture line was partially visible (score 2). Inconsistent and asymmetric formation of periosteal callus was formed due to stabilization of distal femur fractures with periarticular locking plates (Lujan et al., 2010). According to Gupta (2015), primary soft callus was formed on $15^{\text {th }}$ post operative day and then this primary callus was transformed into secondary callus on $30^{\text {th }}$ day of post operatively without any evidence of bridging in goats. On $8^{\text {th }}$ week of postoperative period, two cases i.e. $25 \%$ of cases showed score 0 , five cases showed score 2 and in one case i.e. in $12.5 \%$ of case showed score 2. Gupta (2015) and Kumar (2016) observed that bridging of fracture line and complete union was seen on $8^{\text {th }}$ week of post operative period. Similar finding also reported by Johnson et al., (1996), Nadkarni et al., (2008), Raghunath and Singh (2008), Manjunatha et al., (2011), Coutinho (2012), Sirin et al., (2013).

\section{Group II}

On $2^{\text {nd }}$ week of post-operative period, no evidence of callus formation was seen in four cases i.e. $50 \%$ of cases (score 0) except in four cases showed score 1. Formation of endosteal callus has not been prominent however minimal periosteal callus bridging fractured segments was noted which was correlated clinically with presence of rigid stability and absence of crepitation on $2^{\text {nd }}$ week of post operative period (Patel et al., 2018). On $4^{\text {th }}$ week of post-operative period, two cases i.e. $25 \%$ of cases showed score 1 and six cases i.e. $75 \%$ of cases showed score 2. 
Fig.1 No weight bearing on affected limb

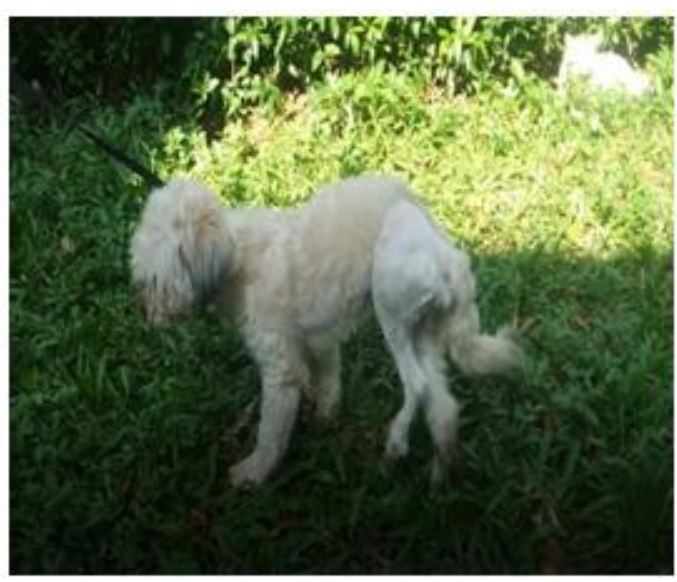

Fig.4 Touching toe

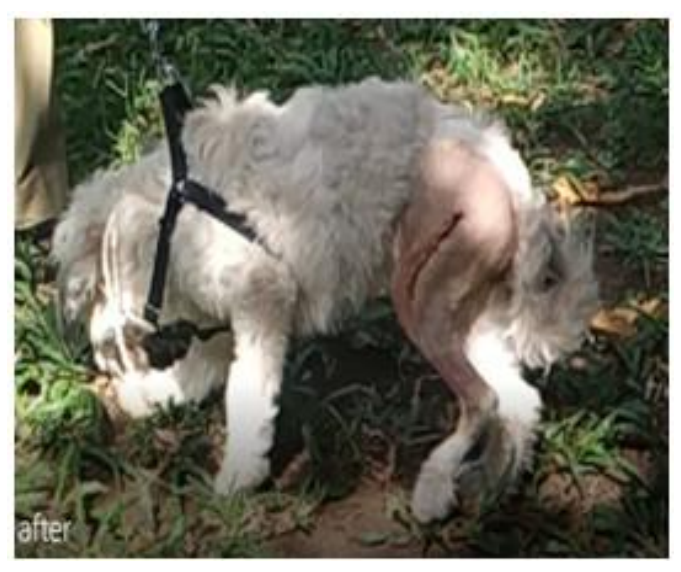

Fig.2 Bone fragments

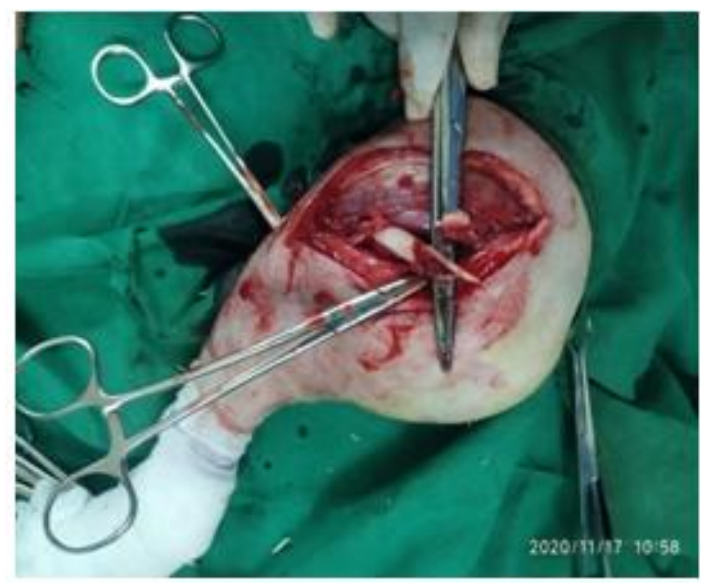

Fig.5 Touching Paw

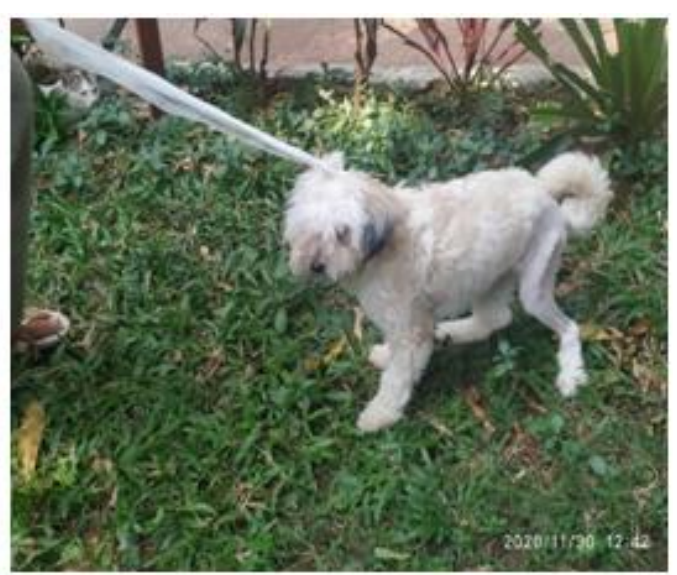

Fig.3 Biosynthetic bone graft

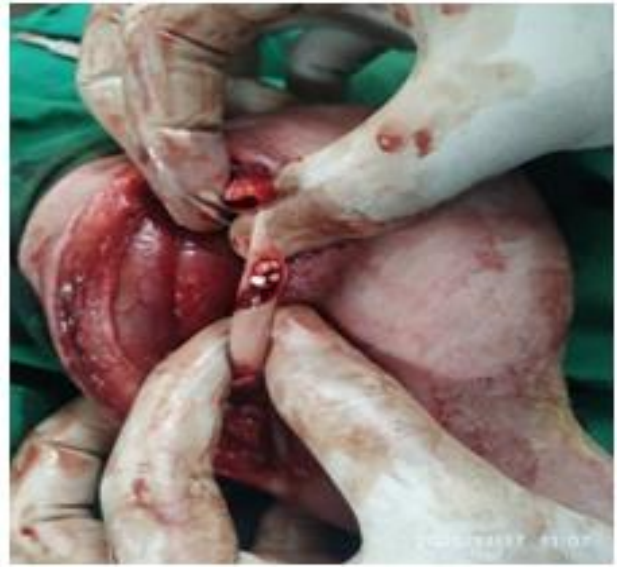

Fig.6 Complete Weight bearing

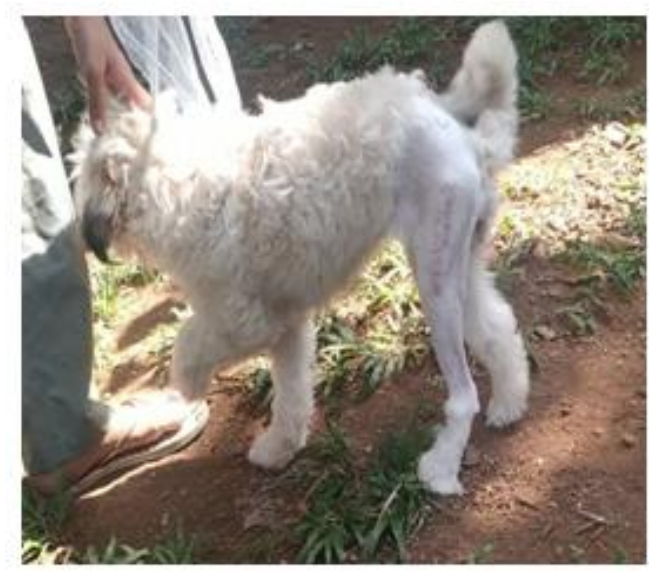




\section{Radiographic examination}

Fig.7 Before Surgery
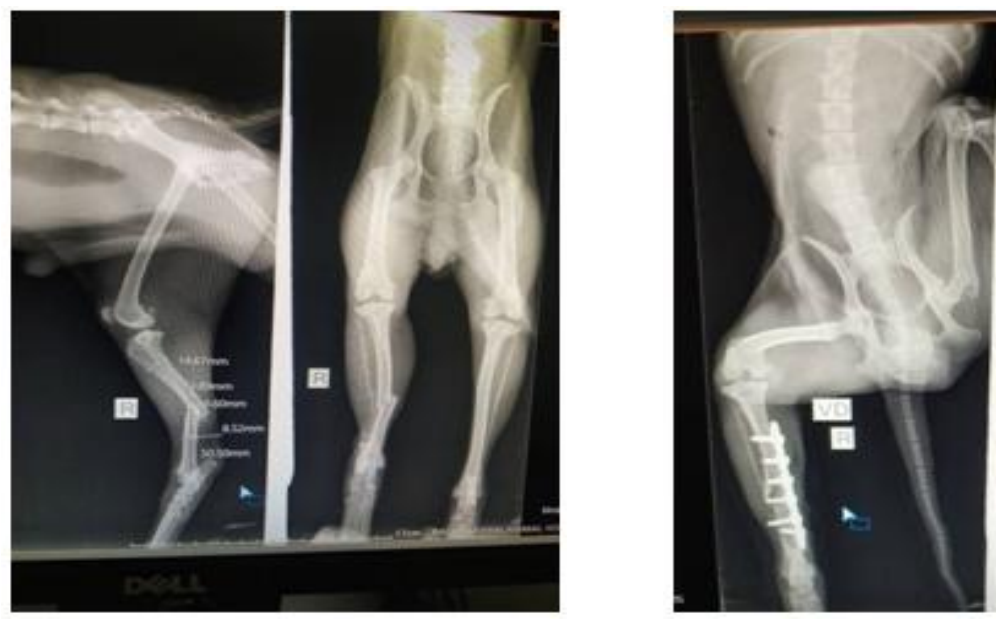

Fig.10 $4^{\text {th }}$ week of post operative

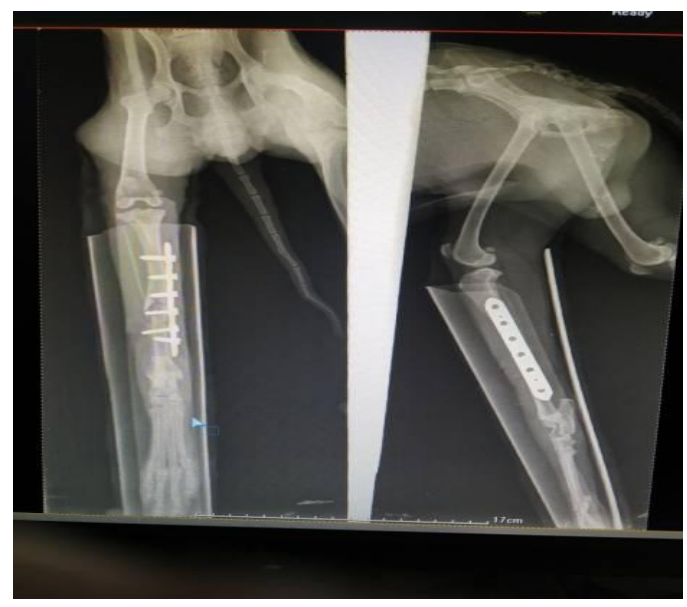

Fig.9 $2^{\text {nd }}$ week of post operative
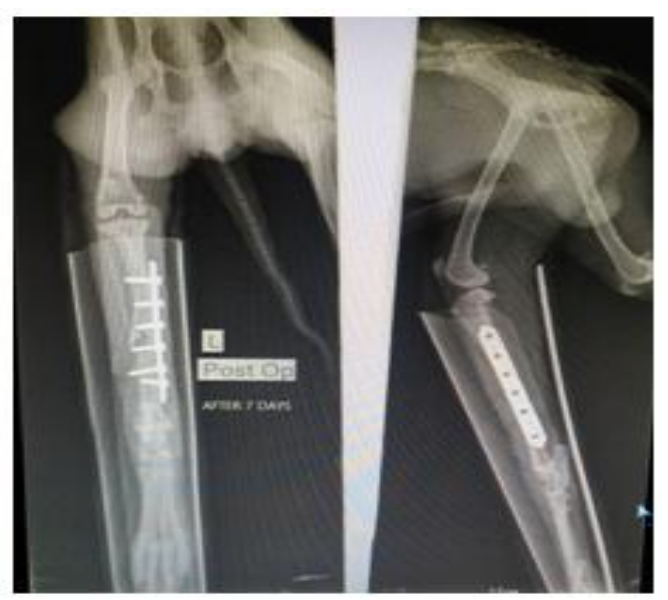

Fig.11 $8^{\text {th }}$ week of post operative period

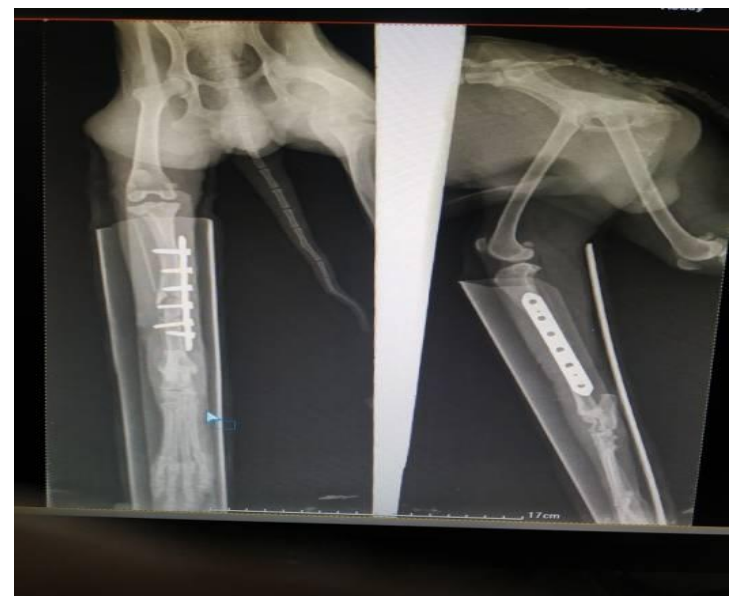


Fig.12 Before
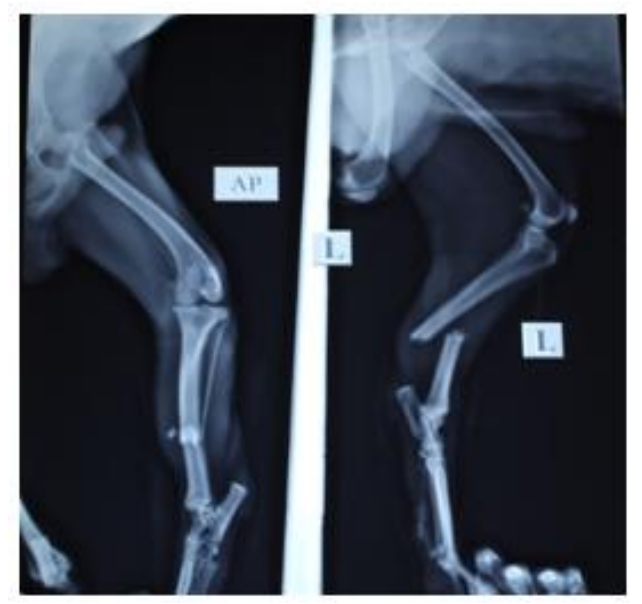

Fig.15 $4^{\text {th }}$ week

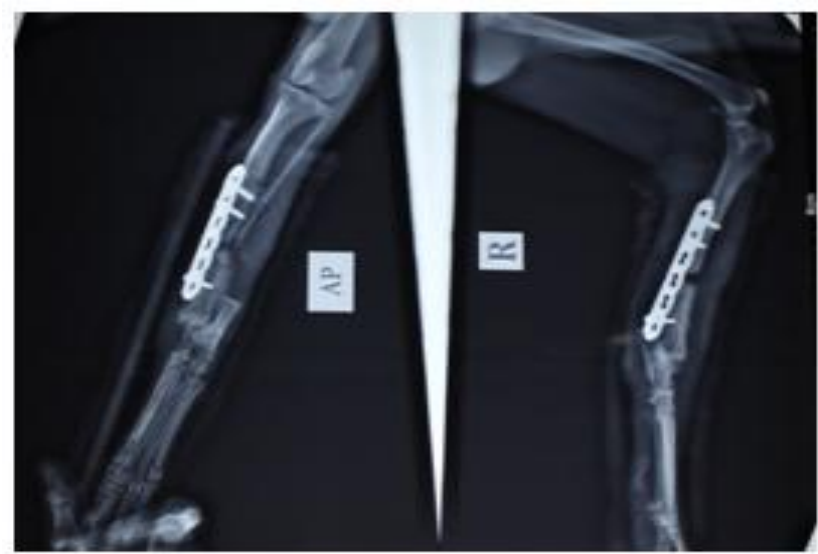

Fig.13 Just after
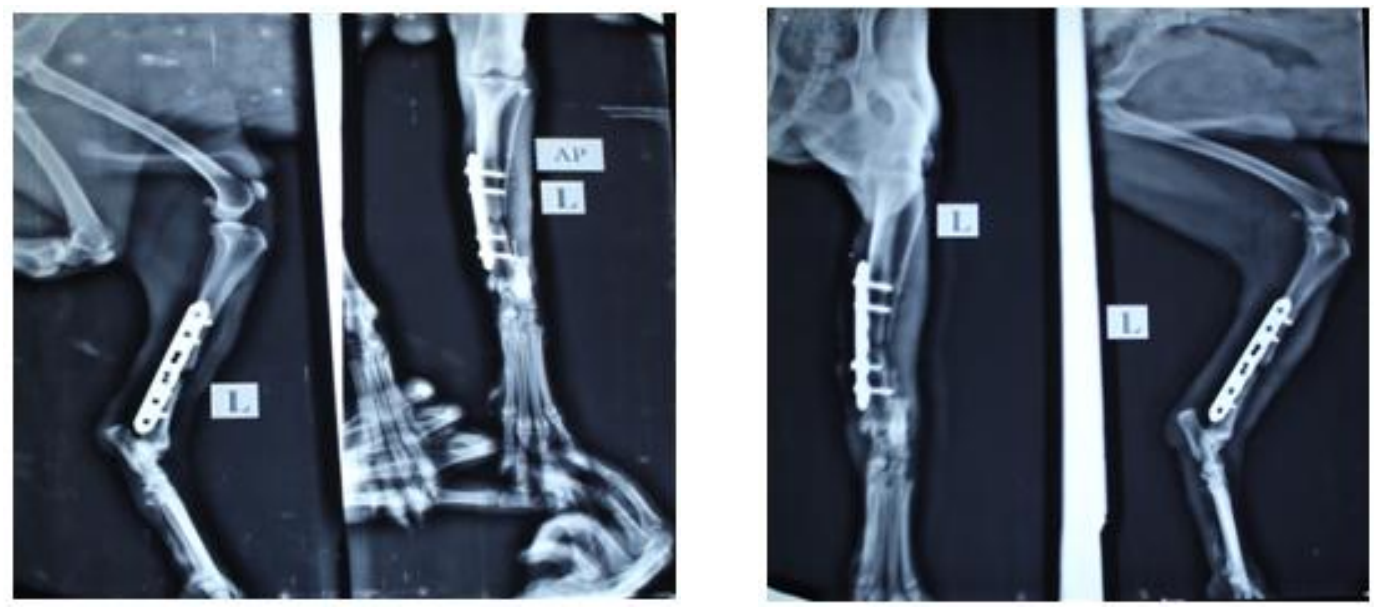

Fig.16 $8^{\text {th }}$ week
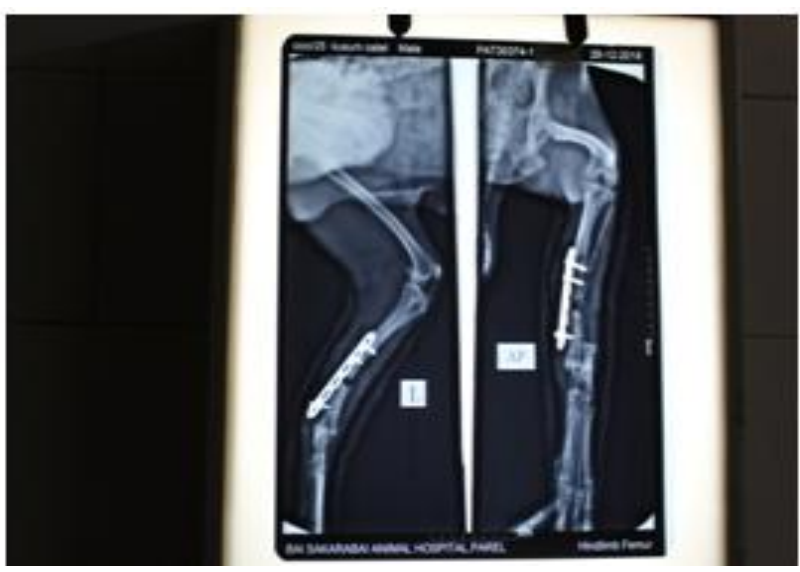
Fig.17 Before

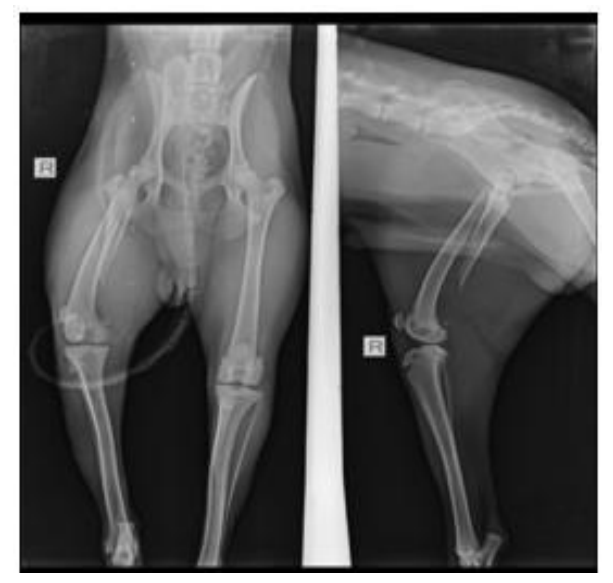

Fig.20 $4^{\text {th }}$ week

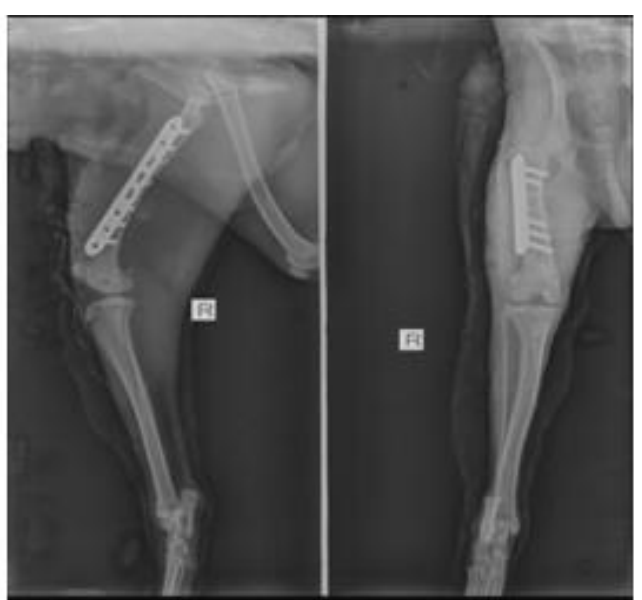

Fig.18 Just after

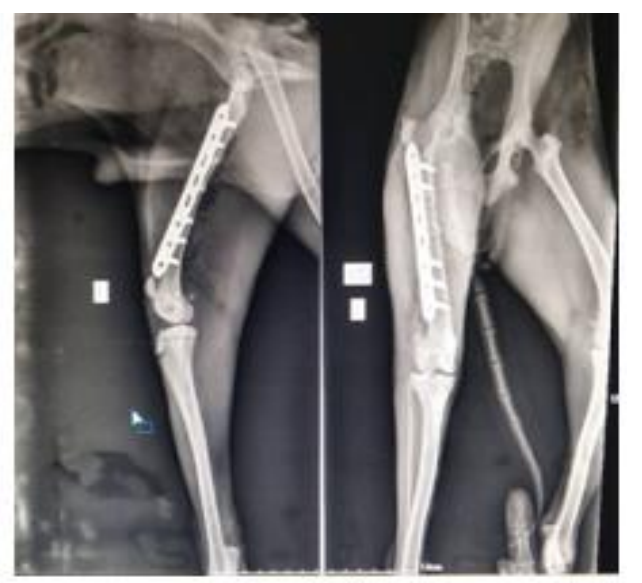

Fig.19 $2^{\text {nd }}$ week

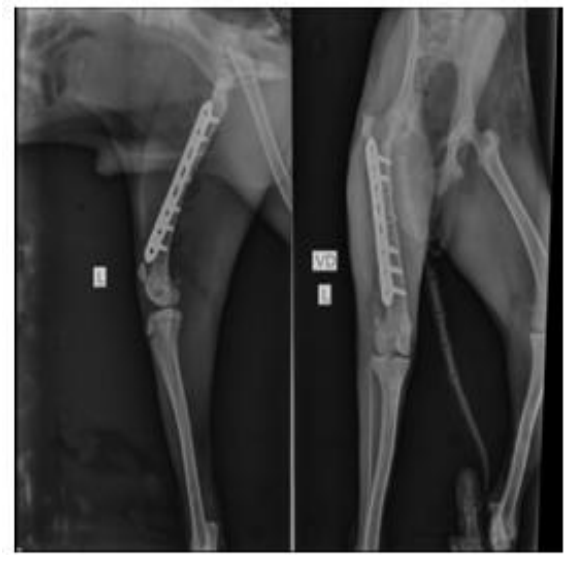

Fig.21 $8^{\text {th }}$ week

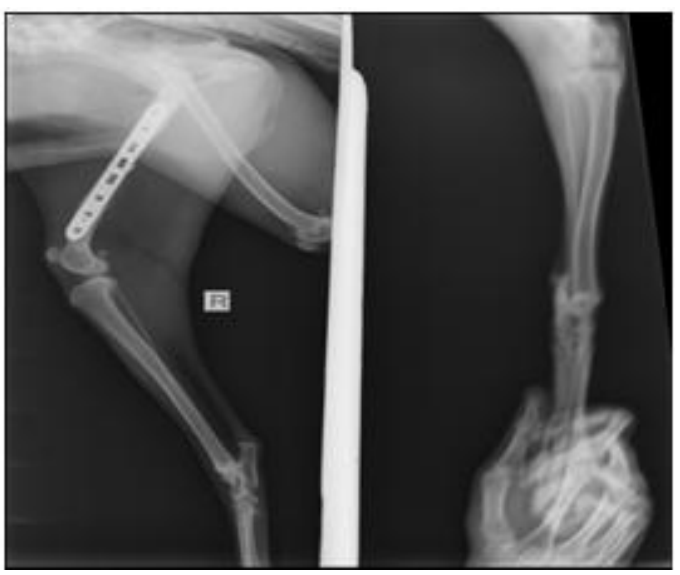


Fig.22 Before

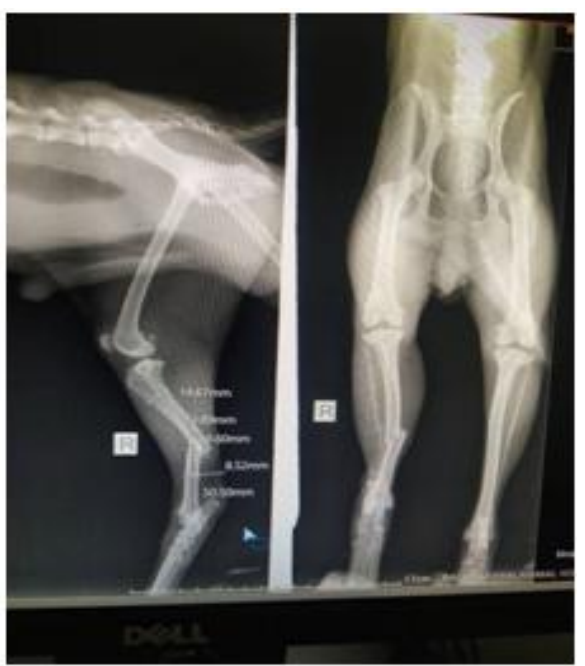

Fig.25 $4^{\text {th }}$ week of post operative

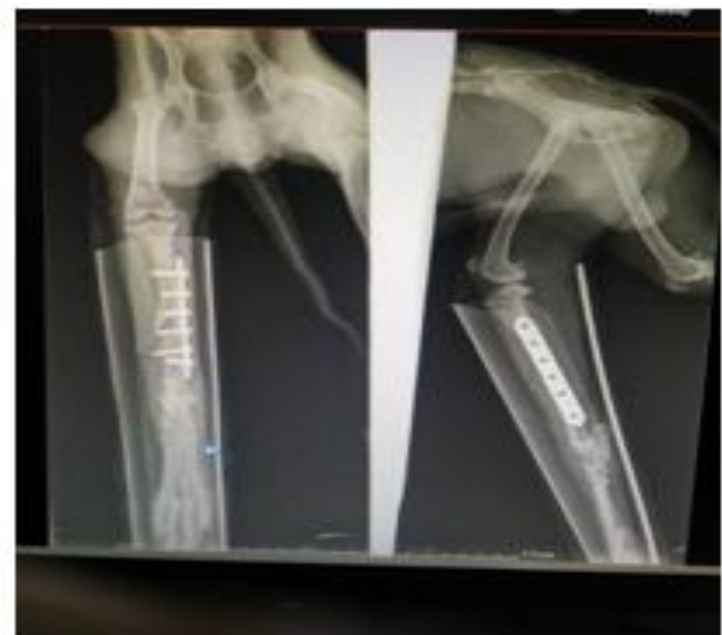

Fig.23 Just after
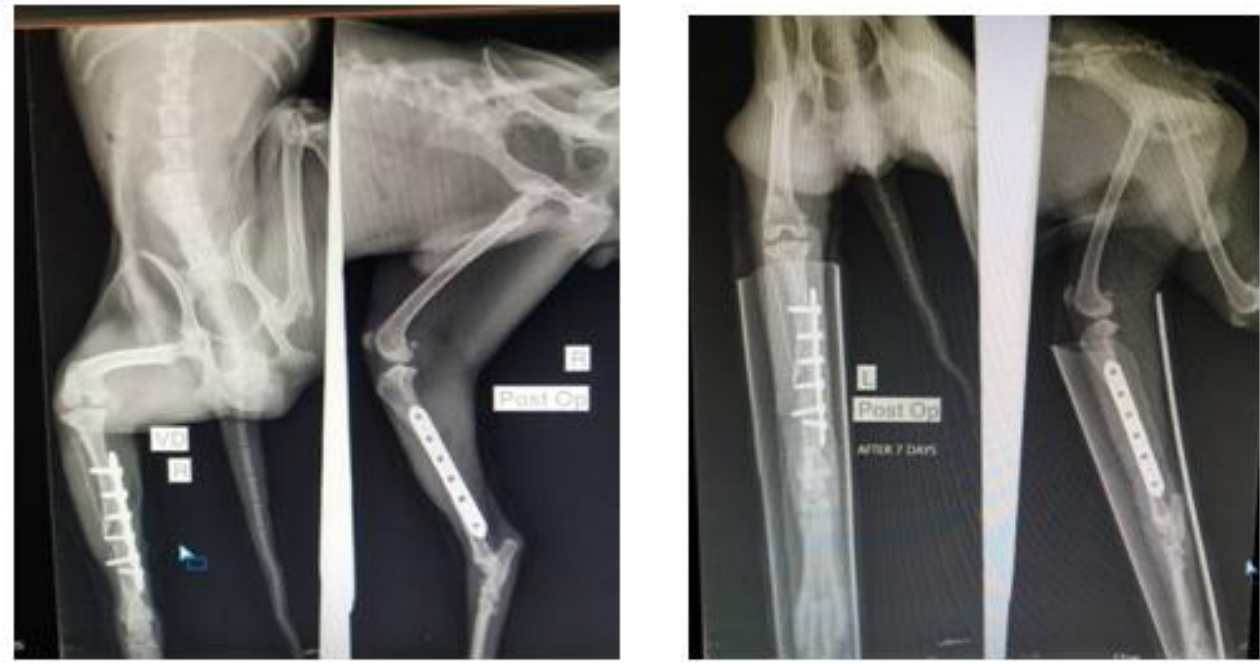

Fig.26 $8^{\text {th }}$ week of post operative

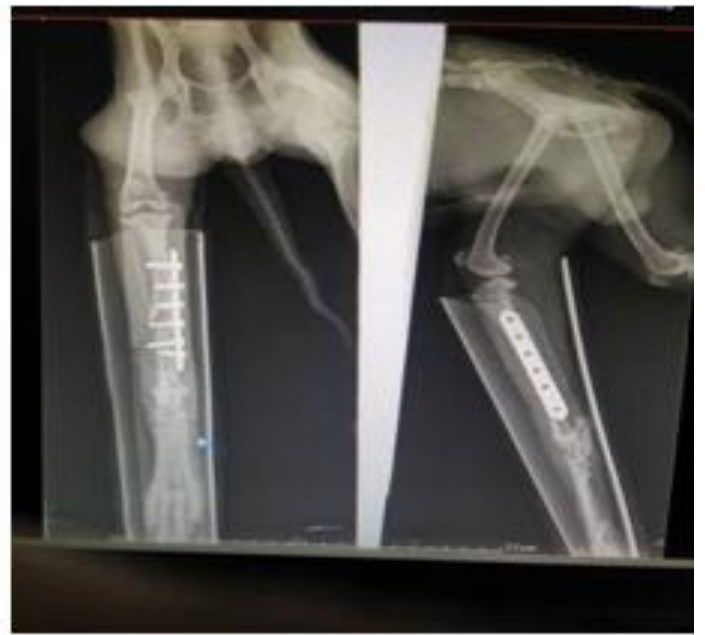


Fig.27 Before
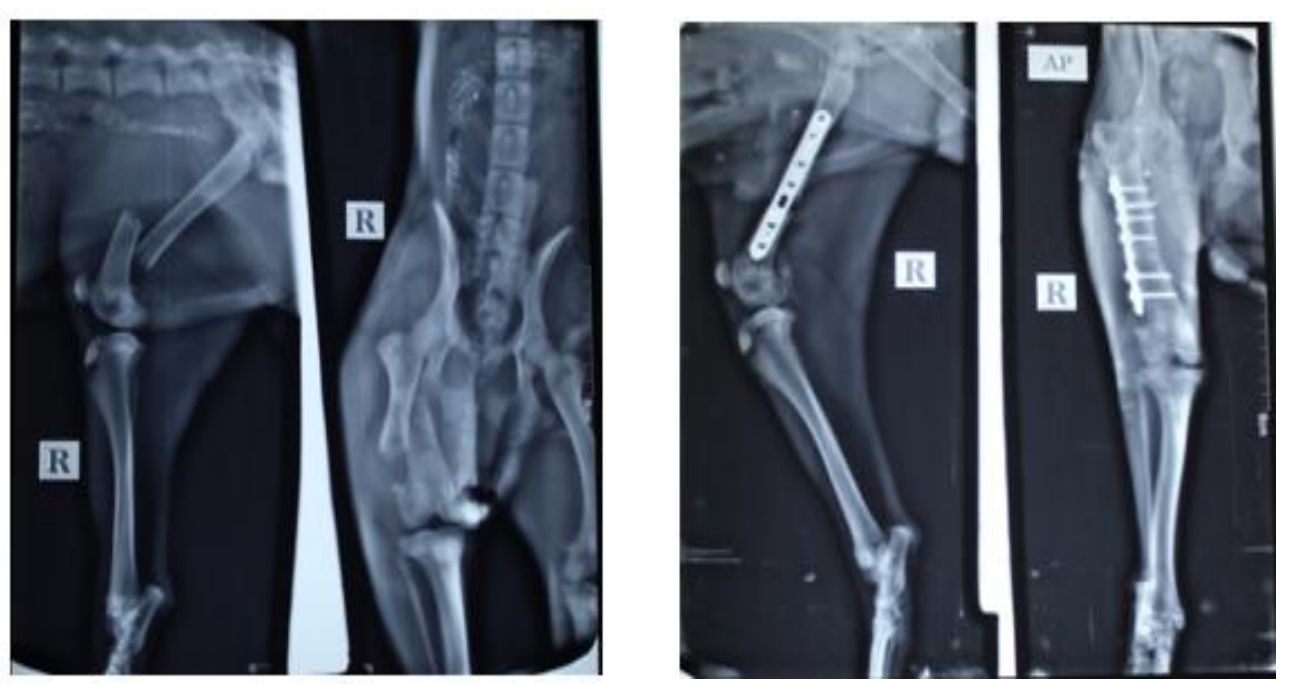

Fig.29 $2^{\text {nd }}$ week
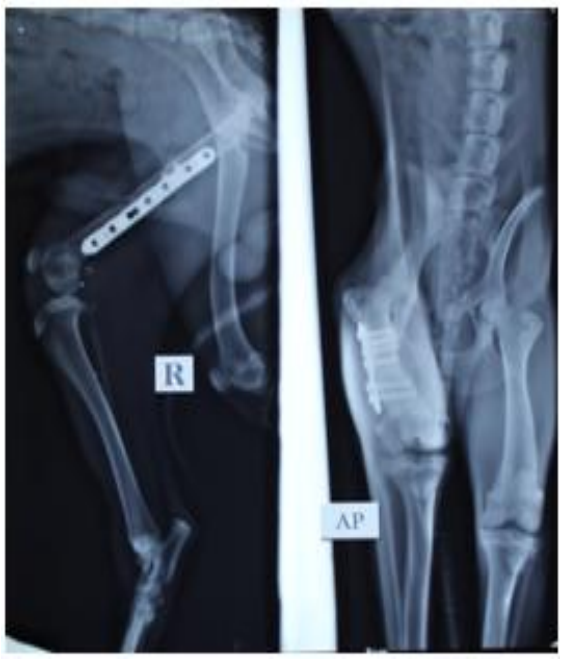

Fig.30 $4^{\text {th }}$ week

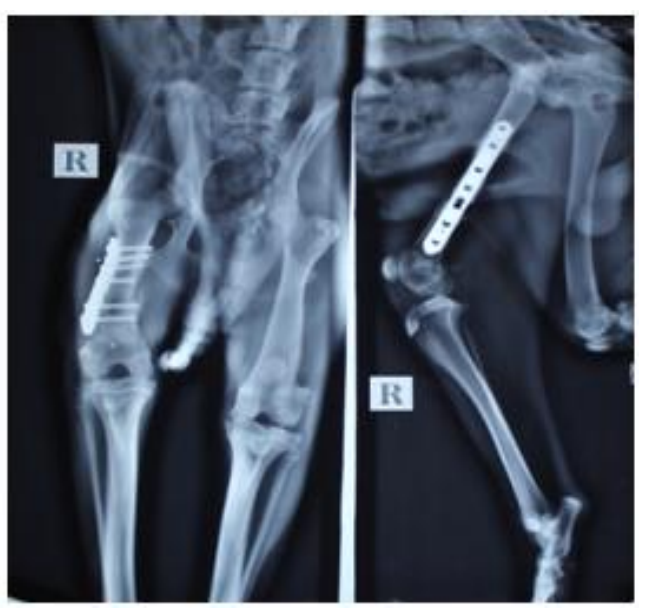

Fig.31 $8^{\text {th }}$ week

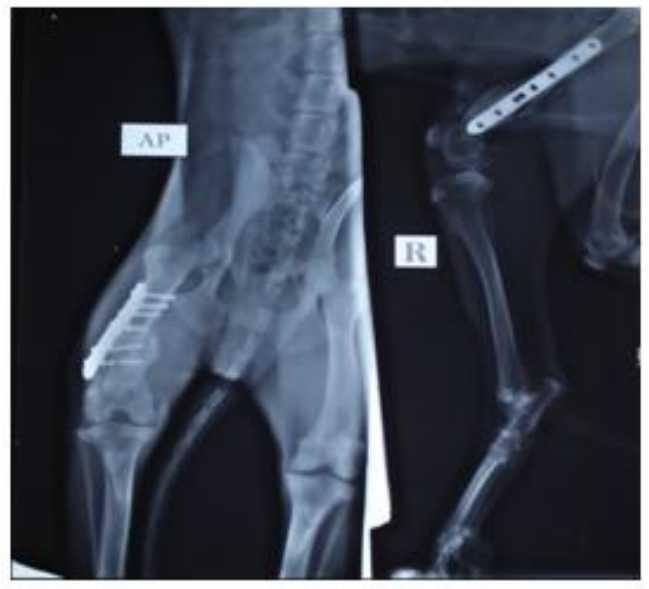


Table.1 Radiographic Scoring system

\begin{tabular}{|c|c|}
\hline Criteria & Score \\
\hline Bone Formation \\
\hline No evidence of bone formation & 0 \\
\hline Bone formation (25\% of the gap) & 1 \\
\hline Bone formation (50\% of the gap) & 2 \\
\hline Bone formation (75\% of the gap) & 3 \\
\hline Bone formation (100\% of the gap) & 4 \\
\hline \multicolumn{2}{|c|}{ Union } \\
\hline Full fracture line & 0 \\
\hline Partial fracture line & 2 \\
\hline Absent fracture line & 4 \\
\hline
\end{tabular}

According to Doijode et al., (2018), formation of bridging callus around the fracture line with the fracture fragments in proper alignment was observed on $30^{\text {th }}$ day. On $8^{\text {th }}$ week ofpostoperative period, one cases i.e. $12.5 \%$ of cases showed more radiopaque shadow suggestive of ossification of callus covering $50 \%$ of the gap (score 2) and seven cases i.e. $87.5 \%$ of cases showed callus formation, 75 $\%$ of the gap (score 3). Vardhan et al., (2017) found that after $60^{\text {th }}$ post-operative day,total resorption of exuberant callus i.e. secondary callus was formed at the fractured site. The observations on $60^{\text {th }}$ day revealed complete union of bones with absence of fractured line (Doijode et al., 2018). Adamiak and Rotkiewicz (2010) from their studies on tibial fractures in sheep reported that there was complete bone union radiologically in between days $52^{\text {nd }}$ to $68^{\text {th }}$ day of after surgery. Pike et al., (2012) found that, there was good union after 8 weeks in 6 out of 13 dogs treated with PMMA.

\section{Group III}

On $2^{\text {nd }}$ week ofpost-operative, $50 \%$ of cases no periosteal reaction was observed while four cases i.e. $50 \%$ of cases depicted initiation of periosteal reaction at a distance from the fracture line with mild radio dense material was seen. In all the cases of this group, full fracture line was distinct (score 0 ). The callus appeared slightly less radio dense with a barely discernable in fracture line by impregnating Biphasic calcium phosphate in case of goats (Gupta, 2015).On $4^{\text {th }}$ week of post-operative, $25 \%$ of cases showed initiation of periosteal reaction at a distance from the fracture line and fracture line was distinct (score 0) and $75 \%$ of cases revealed primary callus formation between the periosteal and intercortical space. Bridging callus was beginning to form between the fractured fragments. The fracture gap had reduced and the fracture line was partially visible (score 2). The width of callus was wider and densities of callus also higher when Biphasic calcium phosphate was utilized in process of fracture healing (Rao et al., 2001). On $8^{\text {th }}$ week of post-operative period, $12.5 \%$ of cases revealed primary callus formation between the periosteal and intercortical space. Bridging callus was beginning to form between the fractured fragments and the area of bone loss. The fracture gap had reduced and the fracture line was partially visible (score 2 ) and $87.5 \%$ of cases showed bridging callus had almost formed wherein the fracture fragments along with the area due to bone loss had almost fused and the fracture line was partially visible (score 2).

The mean time taken for entire surgical 
procedure starting from initial skin incision to application of last skin suture for group I, II and III was 86.25 minutes, 99.37 minutes and 95.62 minutes, respectively.

\section{References}

Aithal H. P., G. R. Singh, and G. S. Bisht (1999) Fractures in dogs: survey of 402 cases. Indian Journal of Veterinary Surgery 20: 15-21.

Ali L. M. (2013) Incidence, Occurrence, Classification and Outcome of Small Animal Fractures: A Retrospective Study (2005-2010). International Journal of Biological, Biomolecular, Agricultural, Food and Biotechnological Engineering 7(3): 191-196

Arora Manit, Edward K S Chan, Sunil Gupta, Ashish D Diwan (2013) Polymethylmethacrylate bone cements and additives: A review of the literature, World J Orthop; 4(2): 67-74, doi:10.5312/wjo.v4.i2.67

Balagopalan T. P., C. B. Devanand, K. Rajankutty, T. Sarada, S. R. Nayar, C. A. Varkey, A. M. Jalaluddin, K. N. Nayar and P. O. George (1995) Fracture in dogs- A review of 208 cases. Indian Journal of Veterinary Surgery 16:41-43.

Burns C. G. (2010) Influence of Locking Bolt Location on the Mechanical Properties of an Interlocking Nail in the Canine Femur. Master's Thesis, Graduate School of The Ohio State University, USA

Chavan S. R. (2013) Evaluation of locking compression plate system for long bone fracture repair in dogs: A clinical study. M. V. Sc. thesis submitted to Maharashtra Animal and Fishery Sciences University, Nagpur, India.

Coutinho N. R. (2012) Evaluation of interlocking nail for long bone fracture repair in dogs: a clinical study. Unpublished M. V. Sc. thesis submitted to Maharashtra Animals and Fishery Sciences University, Nagpur, Maharashtra

Doijode Vinit, Dilip Kumar D and B. V. Shivaprakash (2018) Comparative Evaluation of Veterinary Cuttable Plate and Polypropylene Mesh Impregnated PMMA Plate for Fracture Repair of Tibia Bone in Goats, International Journal of Livestock Research, 8(6), 160-169, doi: 10.5455/ijlr.20170731051307

Egol K. A., E. N. Kubiak, E. Fulkerson, F. J. Kummer and K.J. Koval (2004) Biomechanics of Locked Plates and Screws. Journal of Orthopaedic Trauma 18: 488-493

Gupta P. (2015) Use of interlocking nails for repair of humeral and tibial shaft fractures under image intensifier in dogs. M. V. Sc. thesis submitted to Anand Agricultural University

Hansen B. (2003) Assessment of Pain in Dogs: Veterinary Clinical Studies. ILAR JOURNAL 44(3): 197-205

Johnson K. D., K. E. Frierson, T. S. Keller, C. Cook, R. Scheinberg and J.Zerwekh (1996) Porous ceramics as bone graft substitutes in long bone defects: a biomechanical, histological and radiographic analysis. The Journal of Orthopedic Research 14: 351-369.

Kolata R. J., N. H. Kraut and D. E. Johnston (1974) Patterns of trauma in urban dogs and cats: A study of 1000 cases. Journal of American Veterinary Medical Association 164:499-502

Kumar D. (2016) Efficacy of bone substitutes for fracture healing in goats. Ph. D. thesis (Surgery and Radiology) submitted to Nanaji Deshmukh Veterinary Science University, Jabalpur.

Lane J. M. and H. S. Sandhu (1987) Current 
approaches to experimental bone grafting. Orthop. Clin. North. Am. 18(2): 213-25.

Lujan T. J., C. E. Henderson, S. M. Madey, D. C. Fitzpatrick, J. L. Marsh and M. Bottlang (2010) Locked plating of distal femur fractures leads to inconsistent and asymmetric callus formation. Journal of Orthopaedic trauma 24: 156-162

Maala C. P. and E. M. Celo (1975) A study on the anatomical locations, incidence and causes of fractures in dogs. Phillipine Journal of Veterinary Medicine 14:137-143.

Manjunatha D. R., B. N. Nagaraja, S. Rao, S. Yathiraj and Ranganath, L. (2011) Evaluation of closed and open interlocking nailing for femoral fracture repair in dogs. Indian Journal of Veterinary Surgery 32: 65-66.

Nadkarni B., S. Srivastav, V. Mittal and S. Agarwal (2008) Use of locking compression plates for long bone nonunion without removing existing intramedullary nail: A review of literature and our experience. J. Trauma. 65(2): 485-486.

Phillips I.R. (1979) A survey of bone fractures in the dog and cat. Journal of Small Animal Practice, 20: 661-674.

Raghunath M. and S. S. Singh (2008) Intramedullary interlocking nailing for management of long bone fractures in dogs: A study of 17 clinical cases. Indian J. Vet. Surg. 29 (2): 106-109.

Rajhans M. (2013) Stabilisation of splinters of long bone fracture in dogs. M.V.Sc. \&
A.H. thesis (Surgery and Radiology) submitted to Nanaji Deshmukh Veterinary Science University, Jabalpur.

Rao T. M., G. V. Lakshmipathi, T. P. Sastry and O. Ramakrishna (2001) Biochemical changes following ulnar segmental defect repair with fibrillar collagen-hydroxyappatite and porous hydroxyappatite implants in canines. Indian Journal of Animal Research 35: 112-115.

Simon M. S., R. Ganesh, S. Ayyappan and R. S. Kumar, V. Kundave and B. Das (2011) Incidences of pelvic limb fractures in dogs: A survey of 478cases. Veterinary World 3: 120121

Sirin O. S., U. Kaya and B. Olcay (2013) Clinical and Radiological Outcomes of Locking Compression Plate System in Dogs with Diaphyseal Fractures: 32 Cases. Journal of the faculty of Veterinary Medicine, Kafkas University 19: 13-18

Vardhan H. K., V. Devi Prasad, Makkena Sreenu and N. Syaama Sundar (2017) Radiographic evaluation of poly methylmethacrylate and hydroxy apatite implants for fracture healing in rabbits, International Journal of Science, Environment and Technology, Vol. 6, No 5, 3168 - 3173 Xu X., A. Jin, Y. Liu, J. Liu, X. Zhanq and D. Qin (1998) New concepts and advances of immobilization of long bones. Chinese Medical Journal 111: 174-9.

\section{How to cite this article:}

Dakhane, P. S., D. U. Lokhande, G. S. Khandekar, G. U. Yadav, S. D. Tripathi, S. D. Ingole and Kadam, D. P. 2021. Radiographic Evaluation of Long Bone Fractures by using Antibiotic Loaded Bone Cement (ALBC) and Biosynthetic Bone Graft in dogs. Int.J.Curr.Microbiol.App.Sci. 10(05): 489-501. doi: https://doi.org/10.20546/ijcmas.2021.1005.056 